\title{
The influence of insulin resistance and obesity on left atrial size in Japanese hypertensive patients
}

\author{
Yuji Shigematsu ${ }^{1}$, Sadako Norimatsu ${ }^{2}$, Akiyoshi Ogimoto ${ }^{3}$, Tomoaki Ohtsuka ${ }^{3}$, Hideki Okayama ${ }^{3}$ and \\ Jitsuo Higaki ${ }^{3}$
}

Left atrial (LA) enlargement is an early sign of hypertensive heart disease. Insulin resistance and obesity, integral components of metabolic syndrome, are closely associated with the development of hypertension. However, few echocardiograhic studies have assessed the relations of insulin resistance and obesity to LA size in hypertensive patients. We enrolled 106 never-treated hypertensive patients ( 57 men and 49 women) to assess the possible relations of insulin resistance and obesity to LA size. Insulin resistance was estimated using the homeostasis model assessment (HOMA) formula. Echocardiographically determined LA dimension, left ventricular (LV) mass and relative wall thickness (RWT) were measured as markers of LA size, LV hypertrophy and LV geometry. The EIA ratio estimated by transmitral flow velocity was measured as a marker of LV diastolic function. In addition, body mass index (BMI) was calculated as weight $(\mathrm{kg})$ divided by height $(\mathrm{m})^{2}$ as a marker of obesity. Multivariable regression analyses showed that BMI was the strongest independent predictor of LA size $(P<0.0001)$, followed by the HOMA value $(P=0.0003)$. However, LV mass, RWT and the $E / A$ ratio did not bear significant relations to LA size. There were no sexspecific differences in the relations of HOMA value or BMI to LA size. In conclusion, LA size is influenced by insulin resistance and obesity, integral components of the metabolic syndrome, independently of LV hypertrophy, LV geometry or LV diastolic function in nondiabetic Japanese hypertensive patients.

Hypertension Research (2009) 32, 500-504; doi:10.1038/hr.2009.41; published online 17 April 2009

Keywords: essential hypertension; left atrial size; insulin resistance; LV hypertrophy; obesity

\section{INTRODUCTION}

Left atrial (LA) enlargement diagnosed by electrocardiography is an early sign of hypertensive heart disease. ${ }^{1}$ LA enlargement is also predictive of future ischemic stroke, atrial fibrillation and cardiac death. ${ }^{2-4}$ The factors leading to atrial enlargement in the absence of mitral valve disease are not well established. Echocardiographically determined LA size in hypertension has been related to systolic blood pressure (BP) and left ventricular (LV) hypertrophy in older patients with isolated systolic hypertension. ${ }^{5}$ Furthermore, echocardiographic studies in men with mild-to-moderate hypertension have suggested age, obesity and race as other important risk factors of LA enlargement. $^{6}$

The metabolic syndrome consists of a cluster of atherosclerotic risk factors, including obesity, hypertension, insulin resistance and dyslipidemia. Many atherosclerotic risk factors are also implicated in the pathogenesis of atrial fibrillation. ${ }^{7,8} \mathrm{~A}$ recent study in Japan has shown the relation between metabolic syndrome and the development of atrial fibrillation. ${ }^{9}$

Although obesity and insulin resistance play an important role in the pathogenesis of metabolic syndrome, the precise relation between insulin resistance and obesity to LA size has not been assessed in Japanese hypertensive patients.

Accordingly, the aim of this study was to evaluate the association of LA size with insulin resistance and obesity in nondiabetic and nevertreated Japanese patients with essential hypertension. In addition, we examined the sex-specific relation of insulin resistance and echocardiographic indices of LA and LV structures.

\section{METHODS}

Study population

The study population included 106 nondiabetic patients with essential hypertension (57 men, mean age: $60 \pm 12$ years old; and 49 women, mean age: $62 \pm 10$ years old) and 40 normotensive control (NC) individuals (21 men, 19 women, mean age: $56 \pm 14$ years old). They had normal findings on chemical screening battery and were nondiabetic by the criteria of the American Diabetes Association..$^{10}$ All study patients participated in this study after giving informed consent. The study was carried out in accordance with the Declaration of Helsinki (1989) of the World Medical Association. To exclude the presence of secondary forms of hypertension, atrial fibrillation and valvular heart disease, all patients underwent a complete medical history, physical examinations, echocardiographic examinations and appropriate laboratory evaluation. ${ }^{11}$

\footnotetext{
${ }^{1}$ Clinical Nursing, Ehime University Graduate School of Medicine, Shitsukawa, Toon-city, Ehime, Japan; ${ }^{2}$ Health Science and Basic Nursing, Ehime University Graduate School of Medicine, Shitsukawa, Toon-city, Ehime, Japan and ${ }^{3}$ Division of Cardiology, Department of Integrated Medicine and Informatics, Ehime University Graduate School of Medicine, Shitsukawa, Toon-city, Ehime, Japan

Correspondence: Dr Y Shigematsu, Clinical Nursing, Ehime Graduate School of Medicine, Shitsukawa, Toon-City, Ehime 791-0295, Japan.

E-mail: yujis@m.ehime-u.ac.jp
}

Received 6 November 2008; revised 5 March 2009; accepted 11 March 2009; published online 17 April 2009 


\section{Physical examinations}

Physical examinations in hypertensive patients were supervised by the nursing staff. Weight and height were measured while the subjects were fasting overnight and wearing only underwear. Body mass index (BMI) was calculated as weight $(\mathrm{kg})$ divided by height $(\mathrm{m})^{2}$. BP was measured in triplicate by a single physician who was an expert in the evaluation of hypertension, with an appropriate arm cuff and a mercury sphygmomanometer after a 5 min rest in the sitting position. The arithmetic mean of the last two measurements was calculated. Korotkoff phase V was taken for diastolic BP. Hypertension was defined as systolic BP $140 \mathrm{~mm} \mathrm{Hg}$ and/or diastolic BP $90 \mathrm{~mm} \mathrm{Hg}$.

\section{Biochemical measurements}

In the morning, after an overnight fast, venous blood was sampled for the measurement of plasma concentrations of glucose and insulin, and for serum concentrations of low-density lipoprotein cholesterol, high-density lipoprotein cholesterol and triglycerides. Plasma glucose was immediately determined by the glucose oxidase method. Plasma insulin was determined in duplicate by high specific and sensitive immunoradiometric assay (Abbott Japan, Tokyo, Japan; intra-assay coefficient of variation $1.6 \%$, interassay coefficient of variation $2.2 \%)$. Serum concentrations of low-density lipoprotein cholesterol, high-density lipoprotein cholesterol and triglycerides were assessed by standard enzymatic methods.

Insulin resistance was assessed from fasting immunoreactive insulin (FIRI) and fasting plasma glucose (FPG) and from the earlier validated homeostasis model assessment (HOMA); ${ }^{12}$ thus, HOMA value=FIRI $(\mathrm{pmol} / \mathrm{l}) \times$ FPG $(\mathrm{mmol} / \mathrm{l}) / 161$.

\section{Echocardiographic measurements}

Two-dimensionally guided M-mode echocardiography was carried out by standard methods, as outlined earlier, ${ }^{11}$ using an SSD-6500 echocardiograph with a $3.5 \mathrm{MHz}$ transducer (Aloka Inc., Tokyo, Japan). Echocardiographic examinations were carried out and interpreted by the same cardiologist, who was unaware of the patients' data. LA dimension, LV internal dimension (LVID), interventricular septal thickness and posterior wall thickness (PWT) were measured at end diastole and end systole, according to the American Society of Echocardiography Guidelines. ${ }^{13} \mathrm{LV}$ mass was calculated according to a necropsy-validated formula. ${ }^{14} \mathrm{LV}$ mass was also indexed by body surface area. Relative wall thickness (RWT) was measured as follows: RWT $=2 \times(\mathrm{PWTd} /$ LVIDd), where $\mathrm{d}$ is end diastole. Percent fractional shortening was calculated as (LVIDd-LVIDs)/LVIDd $\times 100$, and was used as an indicator of LV systolic function, where $\mathrm{d}$ and $\mathrm{s}$ are end-diastole and end-systole, respectively. Enddiastolic and end-systolic LV volumes were calculated by the Teichholz method $^{15}$ using linear measurements at diastole and systole, as has been validated by invasive and Doppler reference standards. Stroke volume (SV) was calculated as (end-diastolic LV volume-end-systolic LV volume). The ratio of SV to pulse pressure (PP) was used as an indirect measure of aortic compliance. ${ }^{16}$ Peak early transmitral flow velocity $(E)$ and peak late transmitral flow velocity $(A)$ were measured at the tips of mitral leaflets. The $E / A$ ratio was calculated as an indicator of $\mathrm{LV}$ diastolic function. Two-dimensional and color Doppler imaging were also carried out to rule out valvular heart disease and motion abnormality.

\section{Subgroups analysis}

On the basis of the relationship between RWT and LV mass index, 106 hypertensive patients were then divided into four different groups. The partition values of 0.44 for RWT and $108 \mathrm{~g} \mathrm{~m}^{-2}$ (male) or $104 \mathrm{~g} \mathrm{~m}^{-2}$ (female) for LV mass index, the mean +2 s.d. value of NC individuals, were used. The groups consisted of hypertensive patients with normal RWT and LV mass index (normal geometry; $n=43,41 \%$ ); patients with concentric remodeling ( $n=10$, $9 \%)$; patients with concentric hypertrophy $(n=19,18 \%)$; and patients with eccentric hypertrophy $(n=34,32 \%)$.

\section{Statistical analysis}

All values are expressed as mean \pm s.d. One-way analysis of variance was used to evaluate the difference among groups, with Scheffe's correction for multiple comparisons. Correlation coefficients were calculated according to Pearson's method. A multiple regression analysis was also carried out to select appropriate independent variables producing the highest partial correlation with LA size in hypertensive patients. Probability values $<0.05$ were considered statistically significant in all analysis.

\section{RESULTS}

\section{Demographic and clinical characteristics}

The demographic and clinical characteristics of male hypertensive patients, female hypertensive patients and NC individuals are presented in Table 1. There were no significant differences in age and pulse rate. BMI in NC individuals was significantly smaller than that in male and female hypertensive patients. However, there were no significant differences in BMI between male and female hypertensive patients. Office systolic BP, diastolic BP and PP were significantly higher in hypertensive patients than those in NC individuals. Similarly, there were no significant differences in office systolic BP, diastolic $\mathrm{BP}$ and PP between male and female hypertensive patients.

\section{Biochemical and echocardiographic characteristics}

Biochemical and echocardiographic characteristics of the three groups are presented in Table 2. FIRI, HOMA value and low-density lipoprotein cholesterol in hypertensive patients were significantly higher than those in NC individuals. Furthermore, low-density lipoprotein cholesterol in male hypertensive patients was higher than that in female hypertensive patients. High-density lipoprotein cholesterol in male hypertensive patients was lower than that in NC individuals and in female hypertensive patients. There was no significant difference in triglycerides among the three groups.

The LA dimension in hypertensive patients was significantly larger than that in NC individuals. The E/A ratio was also significantly smaller in hypertensive patients than in NC individuals. The LV mass, LV mass index and RWT were largest in male hypertensive patients, followed by those in female hypertensive patients and in NC individuals. Although there was no significant difference in percent FS among the three groups, the SV/PP ratio in hypertensive patients was higher than that in NC individuals.

\section{Relations of insulin resistance, demographic factors to LA size or LV geometry}

As shown in Table 3, LA size was significantly related to BMI, HOMA value and LV mass in hypertensive patients. Table 4 shows the results of multiple regression analyses. Independent determinants of LA size in hypertensive patients were BMI and HOMA value.

\section{Table 1 Patients characteristics}

\begin{tabular}{|c|c|c|c|}
\hline & $\begin{array}{c}\text { Normotensive control } \\
\text { subjects }(\mathrm{n}=40)\end{array}$ & $\begin{array}{c}\text { Male hypertensive } \\
\text { patients }(\mathrm{n}=57)\end{array}$ & $\begin{array}{c}\text { Female hypertensive } \\
\text { patients }(\mathrm{n}=49)\end{array}$ \\
\hline Age (years) & $56 \pm 14$ & $60 \pm 12$ & $62 \pm 10$ \\
\hline $\begin{array}{l}\text { Pulse rate } \\
\text { (beats } \mathrm{min}^{-1} \text { ) }\end{array}$ & $70 \pm 15$ & $68 \pm 10$ & $72 \pm 12$ \\
\hline \multicolumn{4}{|c|}{ Blood pressure $(\mathrm{mm} \mathrm{Hg})$} \\
\hline Systole & $121 \pm 10$ & $162 \pm 15^{* *}$ & $160 \pm 15^{* *}$ \\
\hline Diastole & $70 \pm 9$ & $91 \pm 12^{* *}$ & $87 \pm 11^{* *}$ \\
\hline $\begin{array}{l}\text { Pulse pressure } \\
(\mathrm{mm} \mathrm{Hg})\end{array}$ & $50 \pm 8$ & $71 \pm 12^{* *}$ & $72 \pm 14^{* *}$ \\
\hline $\begin{array}{l}\text { Body mass } \\
\text { index }\left(\mathrm{kg} \mathrm{m}^{-2}\right)\end{array}$ & $22.1 \pm 2.1$ & $24.5 \pm 2.9 *$ & $24.2 \pm 3.7^{*}$ \\
\hline
\end{tabular}

Vales are mean \pm s.d.

${ }^{*} P<0.005$ and ${ }^{* *} P<0.0001$ vs. normotensive control individuals. 
Table 2 Biochemical and echocardiographic characteristics in normotensive control individuals, male and female hypertensive patients

\begin{tabular}{lccc}
\hline & $\begin{array}{c}\text { Normotensive } \\
\text { control } \\
\text { subjects } \\
(\mathrm{n}=40)\end{array}$ & $\begin{array}{c}\text { Male } \\
\text { hypertensive } \\
\text { patients } \\
(\mathrm{n}=57)\end{array}$ & $\begin{array}{c}\text { Female } \\
\text { hypertensive } \\
\text { patients } \\
(\mathrm{n}=49)\end{array}$ \\
\hline Biochemical parameters & & & \\
FPG (mmol I-1) & $5.07 \pm 0.50$ & $5.37 \pm 0.77$ & $5.33 \pm 0.49$ \\
FIRI (pmol I-1) & $29.8 \pm 5.5$ & $51.7 \pm 24.4^{* *}$ & $47.4 \pm 23.7^{* *}$ \\
HOMA value & $0.92 \pm 0.20$ & $1.76 \pm 0.97^{* *}$ & $1.58 \pm 0.84^{* *}$ \\
LDL-C (mmol I-1) & $2.81 \pm 0.52$ & $3.34 \pm 0.88^{* *}$ & $3.16 \pm 0.73^{* *,}$ \\
HDL-C (mmol I-1) & $1.43 \pm 0.53$ & $1.19 \pm 0.35^{* *}$ & $1.40 \pm 0.38^{\#}$ \\
TG (mmol I-1) & $1.61 \pm 0.62$ & $1.76 \pm 0.69$ & $1.67 \pm 0.85$ \\
& & & \\
Echocardiographic parameters & & & \\
LA dimension (cm) & $3.24 \pm 0.43$ & $3.55 \pm 0.45^{* *}$ & $3.43 \pm 0.52^{*}$ \\
EIA ratio & $1.08 \pm 0.41$ & $0.73 \pm 0.21^{* *}$ & $0.79 \pm 0.23^{* *}$ \\
LV mass (g) & $131 \pm 25$ & $202 \pm 47^{* *}$ & $155 \pm 36^{* *, \#}$ \\
LV mass index (g m $\left.{ }^{-2}\right)$ & $85 \pm 13$ & $119 \pm 25^{* *}$ & $102 \pm 21^{* *, \#}$ \\
RWT & $0.34 \pm 0.05$ & $0.41 \pm 0.08^{* *}$ & $0.37 \pm 0.06^{*, \#}$ \\
Percent FS (\%) & $38.5 \pm 4.3$ & $37.0 \pm 7.2$ & $38.9 \pm 6.8$ \\
SV/PP ratio & $0.75 \pm 0.21$ & $1.09 \pm 0.31^{* *}$ & $1.01 \pm 0.29^{* *}$
\end{tabular}

Abbreviations: FPG, fasting plasma glucose; FIRI, fasting immunoreactive insulin; FS, fractional shortening, HDL-C, high-density lipoprotein-cholesterol; HOMA, homeostasis model assessment; LDL-C, low-density lipoprotein-cholesterol; LA, left atrial; LV, left ventricular; PP, pulse pressure; RWT, relative wall thickness; SV, stroke volume; TG, triglycerides.

Vales are mean \pm s.d. ${ }^{*} P<0.05$ and ${ }^{*} P<0.01$ vs. normotensive control individuals.

$\# P<0.01$ vs. male hypertensive patients.

Table 3 Simple correlation of left atrial size with demographic and echocardiographic variables in hypertensive patients

\begin{tabular}{lrr}
\hline \multirow{2}{*}{ Variables } & \multicolumn{2}{c}{ Left atrial dimension } \\
\cline { 2 - 3 } & r-value & \multicolumn{1}{c}{ P-value } \\
\hline Age & 0.101 & 0.3049 \\
Systolic blood pressure & 0.034 & 0.7304 \\
Diastolic blood pressure & 0.006 & 0.9508 \\
Pulse pressure & 0.044 & 0.6508 \\
Body mass index & 0.421 & $<0.0001$ \\
HOMA value & 0.402 & $<0.0001$ \\
Left ventricular mass & 0.294 & 0.0022 \\
Relative wall thickness & 0.072 & 0.4663 \\
Percent fractional shortening & 0.103 & 0.2947 \\
ElA ratio & 0.254 & 0.0753 \\
SV/PP ratio & 0.089 & 0.3625 \\
\hline Abbrevions: HOMA, homestasis mol &
\end{tabular}

Abbreviations: HOMA, homeostasis model assessment; PP, pulse pressure; SV, stroke volume.

As indicated in Tables 5 and 6, LV mass and RWT were significantly related to the HOMA value in male hypertensive patients. LV mass was related to BMI in female hypertensive patients. In both sexes, the LA size was significantly related to BMI and the HOMA value. Figure 1 shows the comparison of HOMA values in hypertensive patients with normal geometry $(1.35 \pm 0.74)$, concentric remodeling $(1.79 \pm 0.82)$, concentric hypertrophy $(2.30 \pm 1.13)$ and eccentric hypertrophy $(1.72 \pm 0.86)$. Hypertensive patients with concentric hypertrophy showed the highest HOMA value. Figure 2 shows the comparison of LA dimension in hypertensive patients with normal geometry $(3.43 \pm 0.46 \mathrm{~cm})$, concentric remodeling $(3.34 \pm 0.47 \mathrm{~cm})$, concentric
Table 4 Multiple regression analysis of factors relevant to left atrial size in hypertensive patients

\begin{tabular}{lccr}
\hline & \multicolumn{3}{c}{ Left atrial dimension } \\
\cline { 2 - 4 } Variables & $\beta$ & s.e.m & P-value \\
\hline Systolic blood pressure & -0.090 & 0.003 & 0.3108 \\
Body mass index & 0.353 & 0.013 & $<0.0001$ \\
HOMA value & 0.329 & 0.047 & 0.0003 \\
Left ventricular mass & 0.105 & 0.001 & 0.2855 \\
ElA ratio & -0.115 & 0.254 & 0.3322 \\
& \multicolumn{2}{c}{ Multiple $R^{2}=0.430, P=0.0001$} \\
\hline
\end{tabular}

Abbreviation: HOMA, homeostasis model assessment.

Table 5 Simple correlation of HOMA value with left atrial size, left ventricular mass and relative wall thickness in male and female hypertensive patients

\begin{tabular}{lccccc}
\hline & \multicolumn{4}{c}{ HOMA value } \\
\cline { 2 - 3 } & $\begin{array}{c}\text { Male hypertensive patients } \\
(\mathrm{n}=57)\end{array}$ & $\begin{array}{c}\text { Female hypertensive patients } \\
(\mathrm{n}=49)\end{array}$ \\
\cline { 2 - 3 } \cline { 5 - 6 } Valiables & r-value & P-value & & r-value & P-value \\
\hline Left atrial dimension & 0.375 & 0.0041 & & 0.427 & 0.0022 \\
Left ventricular mass & 0.477 & 0.0002 & & 0.200 & 0.1691 \\
Relative wall thickness & 0.491 & 0.0002 & 0.028 & 0.8483 \\
\hline
\end{tabular}

Abbreviation: HOMA, homeostasis model assessment.

Table 6 Simple correlation of body mass index with left atrial size, left ventricular mass and relative wall thickness in male and female hypertensive patients

\begin{tabular}{|c|c|c|c|c|}
\hline \multirow[b]{3}{*}{ Valiables } & \multicolumn{4}{|c|}{ Body mass index } \\
\hline & \multicolumn{2}{|c|}{$\begin{array}{l}\text { Male hypertensive patients } \\
\qquad(\mathrm{n}=57)\end{array}$} & \multicolumn{2}{|c|}{$\begin{array}{l}\text { Female hypertensive patients } \\
\qquad(\mathrm{n}=49)\end{array}$} \\
\hline & r-value & P-value & r-value & P-value \\
\hline Left atrial dimension & 0.400 & 0.0021 & 0.436 & 0.0017 \\
\hline Left ventricular mass & 0.199 & 0.1376 & 0.415 & 0.0030 \\
\hline Relative wall thickness & 0.014 & 0.9202 & 0.152 & 0.2978 \\
\hline
\end{tabular}

Abbreviation: HOMA, homeostasis model assessment.

hypertrophy $(3.55 \pm 0.36 \mathrm{~cm})$ and eccentric hypertrophy $(3.62 \pm 0.56 \mathrm{~cm})$. There were no significant correlations between LA size and LV geometry in hypertensive patients.

\section{DISCUSSION}

It is widely acknowledged that the metabolic syndrome is a premier risk factor for cardiovascular disease, ${ }^{17,18}$ and this association is partly mediated by its effect on the cardiac structure. ${ }^{19,20}$ Consequently, we have examined the relations of insulin resistance (assessed by the HOMA value) and obesity to LV structure. ${ }^{21}$ This study added to our earlier study by identifying the significant and independent relations of insulin resistance and obesity to echocardiograhically determined LA size in nondiabetic Japanese patients with essential hypertension. 


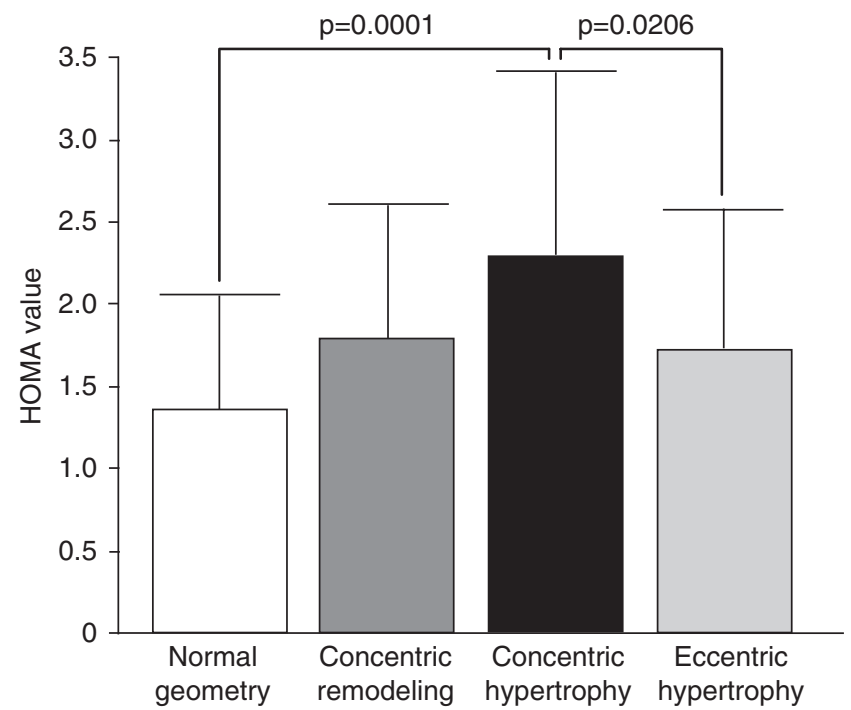

Figure 1 The homeostasis model assessment value associated with different left ventricular patterns in 106 patients with essential hypertension. Values are expressed as the mean \pm s.d.

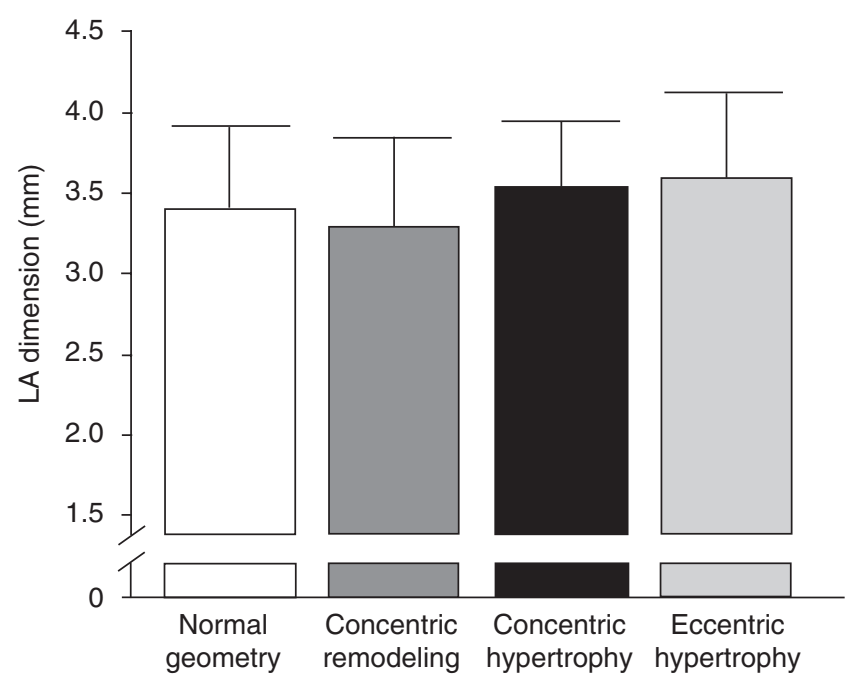

Figure 2 Left atrial (LA) dimension associated with different left ventricular patterns in 106 patients with essential hypertension. Values are expressed as the mean \pm s.d.

Frohlich et al. ${ }^{1}$ have suggested that the electrocardiographic evidence of LA abnormality is an early sign of hypertensive heart disease. On the other hand, insulin resistance and obesity, integral components of metabolic syndrome, are closely associated with the development of hypertension. ${ }^{22,23}$ However, few echocardiograhic studies have assessed the relations of insulin resistance to LA size in hypertensive patients. ${ }^{24,25}$ It is intriguing that in this study, the relation of LV mass to insulin resistance varied between the two sexes, but the LA size was related to insulin resistance in both male and female hypertensive patients. In addition, there was significant association between the LV geometric pattern and the degree of insulin resistance, but no significant correlation was present between LV geometric pattern and LA size. A possible explanation is that LA size may be influenced by clinical factors independent of their impact on LV mass and LV geometry. $^{26}$

Obesity has earlier been suggested to mediate the relation between LA size and LV mass in male hypertensive patients. ${ }^{6}$ However, this study modified this conclusion by finding an independent association of BMI with LA enlargement. Furthermore, the inclusion of insulin resistance in multivariate models eliminated the correlation between LA size and LV mass. The different findings may be explained by major differences in patient characteristics, including the presence of women and less obesity. The Losartan Intervention for End Point Reduction in Hypertension (LIFE) study has shown that LA enlargement was particularly common in women. ${ }^{26}$ The mechanism by which obesity leads to LA enlargement is still under investigation. A relation to hemodynamic changes seen in obese patients, including increased intravascular volume and larger SV and cardiac output, has been suggested. $^{27}$

We found in this study that an increased HOMA value and increased BMI were strongly associated with echocardiographic LA enlargement in hypertensive patients. Hypertension and obesity, integral components of the metabolic syndrome can cause atrial stretch and dilatation, resulting in a structural remodeling predisposing to atrial fibrillation. ${ }^{28,29}$ LA enlargement is a risk for atrial fibrillation. ${ }^{26}$ Furthermore, it has been reported that metabolic syndrome is associated with LA enlargement in patients with nonvalvular atrial fibrillation. ${ }^{30}$ Another possible mechanism by which the metabolic syndrome may predispose to atrial fibrillation is inflammation and oxidative stress. Although not measured in our study, C-reactive protein and oxidants were elevated in patients with atrial fibrillation. ${ }^{31,32}$ Insulin resistance and obesity are associated with a systemic chronic inflammatory response characterized by altered cytokine production and activation of the inflammatory signaling pathway. ${ }^{33,34}$

The meta-analysis, based on 11 randomized controlled trials, indicates that both angiotensin-converting enzyme inhibitors and angiotensin II receptor blockers are effective at preventing the development of atrial fibrillation. ${ }^{35}$ In hypertensive patients treated by Losartan, a reduction in the development of atrial fibrillation was evaluated. ${ }^{36}$ It is widely acknowledged that angiotensin-converting enzyme inhibitors and angiotensin II receptor blockers have a favorable effect on insulin resistance. Therefore, these considerations provide further evidence that insulin resistance is an etiological factor for atrial fibrillation.

The influence of LV diastolic function on the left atrium has been investigated in hypertensive patients. ${ }^{37,38}$ In our earlier study using cardiac MRI, ${ }^{39}$ we reported that LV hypertrophy was an independent determinant of LA enlargement in hypertensive patients. Theoretically, LA enlargement in hypertensive patients with LV hypertrophy can be secondary to the changes in LV diastolic function. Furthermore, we have shown that LV diastolic function was impaired even in hypertensive patients without LV hypertrophy. ${ }^{40}$ In this study, although most hypertensive patients had an impaired LV diastolic function as evaluated by the $E / A$ ratio (abnormal relaxation pattern), the relation between LA enlargement and the E/A ratio was less striking, and the Doppler index was not identified as having an independent association with LA size in multivariate analyses.

A relation between systolic BP and LA size has been reported earlier in the Framingham Heart Study. ${ }^{41}$ Unfortunately, in this study, office systolic BP and PP were not identified as independent determinants of LA size. However, it cannot be excluded that LA enlargement may reflect, at least in part, BP elevation. Long-term average BP was more strictly related to the prevalence of LA enlargement than was in-office 
$\mathrm{BP}^{26,41}$ Therefore, long-term BP control is important for the preventions of LA enlargement and the development of atrial fibrillation.

In conclusion, there is increasing evidence of a link between metabolic syndrome and the development of atrial fibrillation, although the independent effect of metabolic syndrome on LA size is still undetermined. This study indicates that LA size is influenced by insulin resistance and obesity, integral components of the metabolic syndrome, independently of LV hypertrophy, LV geometry and LV diastolic function in nondiabetic Japanese hypertensive patients.

1 Frohlich ED, Tarazi RC, Dustan HP. Clinical-physiological correlations in the development of hypertensive heart disease. Circulation 1971; 44: 446-455.

2 Vaziri SM, Larson MG, Benjamin EJ, Levy D. Echocardiographic predictors of nonrheumatic atrial fibrillation. The Framingham Heart Study. Circulation 1994; 89: 724-730.

3 Benjamin EJ, D'Agostino RB, Belanger AJ, Wolf PA, Levy D. Left atrial size and the risk of stroke death The Framingham Heart Study. Circulation 1995; 92: 835-841.

4 Di Tullio MR, Sacco RL, Sciacca RR, Homma S. Left atrial size and the risk of ischemic stroke in an ethnically mixed population. Stroke 1999; 30: 2019-2024.

5 Pearson AC, Gudipati C, Nagelhout D, Sear J, Cohen JD, Labovitz AJ. Ehocardiographic evaluation of cardiac structure and function in elderly subjects with isolated systolic hypertension. J Am Coll Cardiol 1991; 17: 422-430.

6 Gottdiener JS, Reda DJ, Williams DW, Materson BJ. Left atrial size of hypertensive men: influence of obesity, race and age. J Am Coll Cardiol 1997; 29: 651-658.

7 Wang TJ, Parise H, Levy D, D'Agostino Sr RB, Wolf PA, Vasan RS, Benjamin EJ. Obesity and the risk of new-onset atrial fibrillation. JAMA 2004; 292: 2471-2477.

8 Dublin S, French B, Glazer NL, Wiggins KL, Lumley T, Psaty BM, Smith NL, Heckbert SR. Risk of new-onset atrial fibrillation in relation to body mass index. Arch Internal Med 2006; 166: 2322-2328.

9 Watanabe H, Tanabe N, Watanabe T, Darbar D, Roden DM, Sasaki S, Aizawa Y. Metabolic syndrome and risk of development of atrial fibrillation. The Niigata Preventive Medicine Study. Circulation 2008; 117: 1255-1260.

10 Expert Committee on the Diagnosis Classification of Diabetes Mellitus. Report of the Expert Committee on the Diagnosis and Classification of Diabetes Mellitus. Diabetes Care 1997; 20: 1183-1197.

11 Shigematsu Y, Hamada M, Mukai M, Matsuoka H, Sumimoto T, Hiwada K. Clinical evidence for an association between left ventricular geometric adaptation and extracardiac target organ damage in essential hypertension. J Hypertens 1995; 13: $155-160$.

12 Matthews DR, Hosker JP, Rudenski AS, Naylor BA, Treacher DF, Turner RC. Homeostasis model assessment: insulin resistance and beta-cell function from fasting plasma glucose and insulin concentration in man. Diabetologia 1985; 28: 412-419.

13 Sahn DJ, DeMaria A, Kisslo J, Weyman A. The Committee on M-Mode Standardization of the American Society of Echocardiography. Recommendations regarding quantitation in M-mode echocardiography: results of a survey of echocardiographic measurements. Circulation 1978; 58: 1072-1083.

14 Devereux RB, Alonso DR, Lutas EM, Gottlieb GJ, Campo E, Sachs I, Reichek N. Echocardiographic assessment of left ventricular hypertrophy: comparison with necropsy findings. Am J Cardiol 1986; 57: 450-458.

15 Teichholz LE, Kreulen T, Herman MV, Golin R. Problems in echocardiographic volume determinations. echocardiographic-angiographic correlations in the presence or absence of asynergy. Am J Cardiol 1976; 37: 7-11.

16 Ferguson JJ, Julius S, Randall OS. Stroke volume-pulse pressure relationships in borderline hypertension: a possible indicator of decreased arterial compliance. J Hypertens 1984; 2 (suppl 3): 397-399.

17 Ruige JB, Assendelft WJJ, Dekker JM, Kostense PJ, Heine RJ, Bouter LM. Insulin and risk of cardiovascular disease: a meta-analysis. Circulation 1998; 97: 996-1001.

18 Fujiwara T, Saitoh S, Takagi S, Takeuchi H, Isobe T, Chiba Y, Miura T, Shimamoto K. Development and progression of atherosclerotic disease in relation to insulin resistance and hyperinsulinemia. Hypertens Res 2005; 28: 665-670.

19 Lind L, Andersson PE, Andren B, Hanni A, Lithell HO. Left ventricular hypertrophy in hypertension is associated with the insulin resistance metabolic syndrome. $J$ Hypertens 1995; 13: 433-438.
20 Verdecchia P, Reboldi G, Schillaci G, Borgioni C, Ciucci A, Telera MP, Santeusanio F, Porcellati C, Brunetti P. Circulating insulin and insulin insulin-like growth factor-1 are independent determinants of left ventricular mass and geometry in essential hypertension. Circulation 1999; 100: 1802-1807.

21 Shigematsu Y, Norimatsu S, Ohtsuka T, Okayama H, Higaki J. Sex-related differences in the relations of insulin resistance and obesity to left ventricular hypertrophy in Japanese hypertensive patients. Hypertens Res 2006; 29: 499-504.

22 Donnelly R, Connell JMC. Insulin resistance: possible role in the aetiology and clinical course of hypertension. Clin Sci 1992; 83: 265-275.

23 Takase H, Dohi Y, Toriyama T, Okado T, Tanaka S, Sato K, Kimura G. Metabolic disorders predict development of hypertension in normotensive Japanese subjects. Hypertens Res 2008; 31: 665-671.

24 Lind L, Berne C, Andren B, Lithell H. Relationship between diastolic hypertension and myocardial morphology and function in elderly males with diabetes mellitus. Diabetologia 1996; 39: 1603-1606.

25 Rutter MK, Parise H, Benjamin EJ, Levy D, Larson MG, Meigs JB, Nesto RW, Wilson PW, Vasan RS. Impact of glucose intolerance and insulin resistance on cardiac structure and function: sex-related differences in the Framingham Heart Study. Circulation 2003; 107: 448-454.

26 Gerdts E, Oikarinen L, Palmieri V, Otterstad JE, Wachtell K, Boman K, Dahlöf B, Devereux RB. Correlates of left atrial size in hypertensive patients with left ventricular hypertrophy the Losartan Intervention For Endpoint Reduction in Hypertension (LIFE) Study. Hypertension 2002; 39: 739-743.

27 Messerli FH, Ventura HO, Reisin E, Otterstad JE, Wachtell K, Boman K, Dahlöf B, Devereux RB. Borderline hypertension and obesity: two prehypertensive states with elevated cardiac output. Circulation 1982; 66: 55-60.

28 Allessie M, Ausma J, Schotten U. Electrical, contractile and structural remodeling during atrial fibrillation. Cardiovasc Res 2002; 54: 230-246.

29 Aime-Sempe C, Folliguet T, Rucker-Martin C, Krajewska M, Krajewska S, Heimburger M, Aubier M, Mercadier JJ, Reed JC, Hatem SN. Myocardial cell death in fibrillating and dilated human right atria. J Am Coll Cardiol 1999; 34: 1577-1586.

30 Nicolaou VN, Papadakis JE, Karatzis EN, Dermitzaki SI, Tsakiris AK, Skoufas PD. Impact of the metabolic syndrome on atrial size in patients with new-onset atrial fibrillation. Angiology 2007; 58: 21-25.

31 Chung MK, Martin DO, Sprecher D, Wazni O, Kanderian A, Carnes CA, Bauer JA, Tchou PJ, Niebauer MJ, Natale A, Van Wagoner DR. C-reactive protein elevation in patients with atrial arrhythmias: inflammatory mechanisms and persistence of atrial fibrillation. Circulation 2001; 104: 2886-2891.

32 Mihm MJ, Yu F, Carnes CA, Reiser PJ, McCarthy PM, Van Wagoner DR, Bauer JA. Impaired myofibrillar energetics and oxidative injury during human atrial fibrillation. Circulation 2001; 104: 174-180.

33 Wellen KE, Hotamisligil GS. Obesity-induced inflammatory changes in adipose tissue. J Clin Invest 2003; 112: 1785-1788.

34 Savage D, Petersen KF, Shulman GI. Mechanisms of insulin resistance in humans and possible links with inflammation. Hypertension 2005; 45: 828-833.

35 Healey JS, Baranchuk A, Crystal E, Morillo CA, Garfinkle M, Yusuf S, Connolly SJ. Prevention of atrial fibrillation with angiotensin-converting enzyme inhibitors and angiotensin receptor blockers A meta-analysis. J Am Coll Cardiol 2005; 45: 1832-1839

36 Wachtell K, Lehto M, Gerdts E, Olsen MH, Hornestam B, Dahlöf B, Ibsen H, Julius S, Kjeldsen SE, Lindholm LH, Nieminen MS, Devereux RB. Angiotensin II receptor blockade reduces new-onset atrial fibrillation and subsequent stroke compared to atenolol: the Losartan Intervention For Endpoint Reduction in Hypertension (LIFE) Study. J Am Coll Cardiol 2005; 45: 712-719.

37 Dreslinski GR, Frohlich ED, Dunn FG, Messerli FH, Suarez DH, Reisin E. Echocardiographic diastolic ventricular abnormality in hypertensive heart disease: atrial emptying index. Am J Cardiol 1981; 47: 1087-1090.

38 Inouye I, Massie B, Loge D, Topic N, Silverstein D, Simpson P, Tubau J. Abnormal left ventricular filling: an early finding in mild to moderate systemic hypertension. $A m \mathrm{~J}$ Cardiol 1984; 53: 120-126.

39 Mineoi K, Shigematsu Y, Ochi T, Hiwada K. Left ventricular mass and atrial volume determined by cine magnetic resonance imaging in essential hypertension. Am J Hypertens 2000; 13: 1103-1109.

$40 \mathrm{Li}$ L, Shigematsu Y, Hamada M, Hiwada K. Relative wall thickness is an independent predictor of left ventricular systolic and diastolic functions in essential hypertension. Hypertens Res 2001; 24: 493-499.

41 Vaziri SM, Larson MG, Lauer MS, Benjamin EJ, Levy D. Influence of blood pressure on left atrial size. The Framingham Heart Study. Hypertension 1995; 25: 1155-1160. 